\title{
Analysis of the resistance frame of the equipment for opening and compartmentalizing watering furrows, using 3D finite elements
}

\author{
Petru Cardei ${ }^{1,{ }^{*}}$, Marius Oprescu ${ }^{2}$, Nicolae Constantin ${ }^{1}$, Ștefan-Sorin Biriș ${ }^{3}$, and Sebastian \\ Muraru $^{1}$ \\ ${ }^{1}$ INMA Bucharest, RDI, Bv. Ion Ionescu de la Brad no 6 Bucharest, Romania \\ ${ }^{2}$ INMA Bucharest, DITRMA, Bv. Ion Ionescu de la Brad no 6 Bucharest, Romania \\ ${ }^{3}$ Politechnic University of Bucharest,
}

\begin{abstract}
The proposed article sets out the results of the finite element structural analysis for the open and compartmentalised watering furrow equipment (OCWFE). It uses a 3D structural model with 3D finite elements. The analysis set out in the article is made in order to determine the field of relative displacement and equivalent stress in the load-bearing structure of the OCWFE. The structural model is generated in CAD-CAM. For the structural analysis, it is necessary the CAE model, which is obtained from the CAD-CAM model, mainly by eliminating gaps and interferences, but also by the techniques of realizing the contact between the components of the assembly and a careful mashing of the structure. The structural model thus created is supported and loaded in accordance with the experimental results from the literature. The relative displacement field and the equivalent stress field within the resistance frame of the OCWFE is obtained following the linear static analysis. The field of relative displacements is used to assess the effects on the quality of the work performed. The equivalent stress field is used to estimate the safety factor of the structure, by reference to the flow stress of the material from which the structure is built.
\end{abstract}

\section{Introduction}

The complexity of agricultural machines generates very varied requirements on their resistance frames (load-bearing structures). In addition to the supports of the working bodies, the resistance frames must also support ancillary assemblies with a functional role, sometimes real installations with an important role in carrying out the work process or in carrying out additional work. In order to meet these requirements, a high-level design is necessary, leading to a resistant structure but also sufficiently supple, optimized, so as not to produce excessive energy consumption. Also, the structure must be designed so as not to occur in the operation process, resonant vibration regimes that lead to poor quality of the

\footnotetext{
* Corresponding author: petru cardei@yahoo.com
} 
work, premature wear and failures. Also, a very important problem of load-bearing structures is the achievement of the high security of human personnel working on agricultural machinery, its protection even in case of serious accidents. For these reasons, the design of load-bearing structures of agricultural machinery is difficult enough to require the help of specialized tools for drawing, calculation and simulation. The study, research, and design of load-bearing structures is a field deeply involved in many disciplines of science and technology: civil engineering, [1-2], automobiles, aircraft or water vehicles, medicine, etc. For agricultural machines through load-bearing structures we understand, most of the time, resistance frames [3-14]. In general, the works [3-14] use 3D finite element analysis for linear-elastic static analysis, implicitly elementary analysis of the strength of structures. There are also works that address the dynamic working regime of assemblies or subassemblies of agricultural machines, problems of modal analysis related to the avoidance of working regimes with resonances, analysis of structural failures using linear and nonlinear analysis, [3]. Also addressed in many papers is the problem of optimizing the strength of agricultural machinery, also using structural models with 3D finite elements, for example $[3,7,11$, and 15]. The analysis presented in this paper is only a simple application of linearly elastic static analysis for the frame of a small dimension machine with precise loading points. The first result presented is the resistance analysis, a common result in the field, the second presenting the possibility to control the quality of soil processing, more precisely, the control of the depth of the irrigation channel created. In the studied literature, we did not find references to resistance studies for agricultural machines of this type, OCWFE. Research on the testing of agricultural equipment in real field conditions was carried out by [22, 24, 28], simulation by finite element analysis (FEM) $[19,23,26,27]$, on special installations / test stands in regime simulated and accelerated $[21,25,26]$ or theoretical research [20], to identify and develop the most modern constructive solutions [29], similar to those carried out worldwide.

\section{Material and method}

The material of this research consists of the load-bearing structure of the OCWFE (fig. 1) and the boundary and loading conditions. The working method is the structural analysis using finite element method with 3D finite elements.

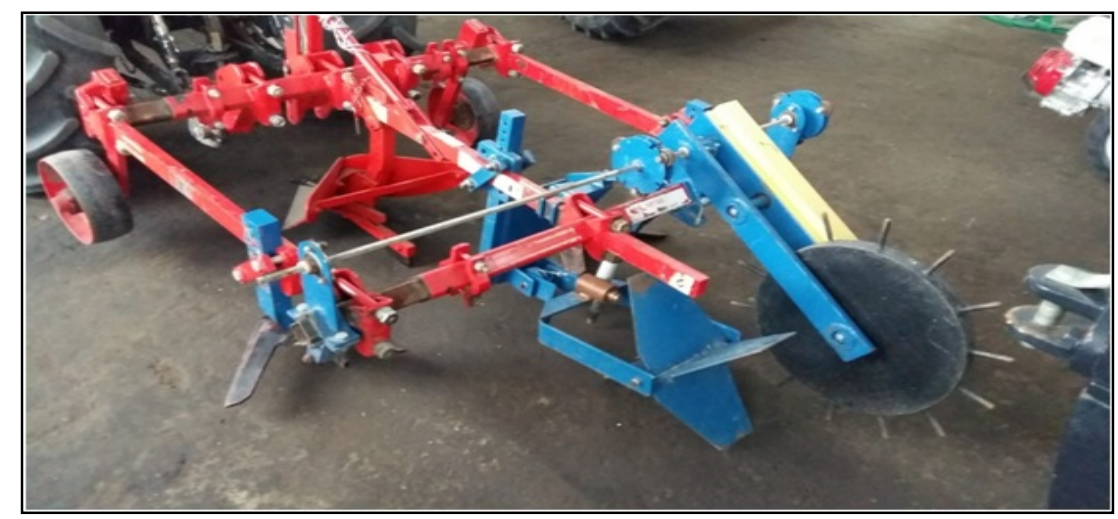

Fig. 1. The open and compartmentalised watering furrow equipment (OCWFE).

The structural model (geometry, boundary conditions and loads), and the meshed structural model, for OCWFE, are given in fig.2. The CAD-CAM model is an extension of the structural model in fig. 2 because it also contains the working members, the double 
mouldboard and the blade, as well as the copy wheel and the drive mechanism of the blade. The CAD-CAE model only takes over the load-bearing structure (resistance frame) with the supports of the double mouldboard and of the blade. To obtain the geometry of the CADCAE model from fig. 2, from the CAD-CAM model were eliminated the working organs and the annexes (the copying wheel and the drive mechanism of the blade). In addition, gaps and interferences have been eliminated from the CAD-CAM model. The effects of the working organs on the structure were substituted with the loads in forces, fig. 2. The conditions on the border consisted in the rigid fixing of the structure in the points of connection to the tractor (cancellation of all degrees of freedom on the borders of the holes where the fastening bolts are found).

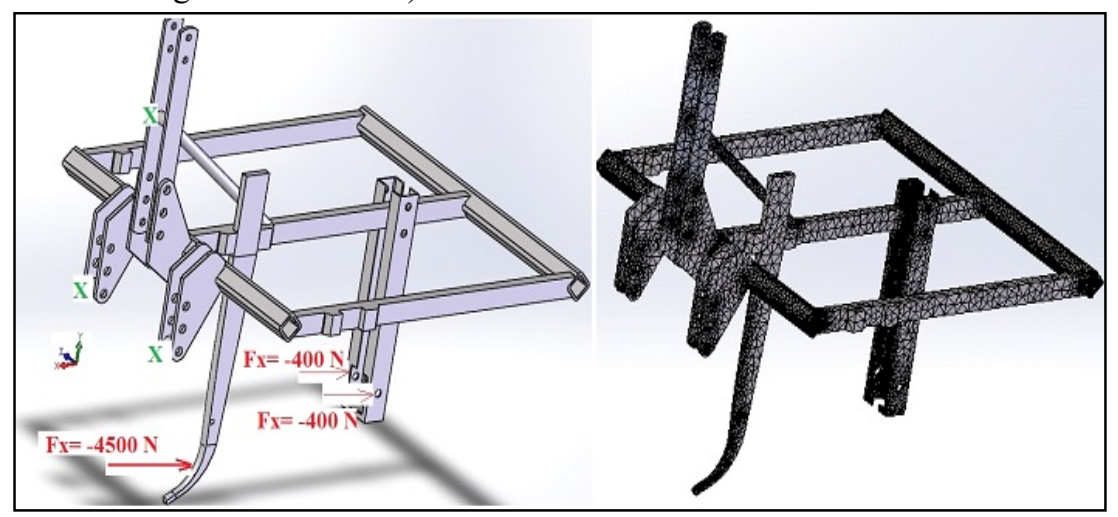

Fig. 2. The structural model (geometry, boundary conditions and loads), left, respectively the meshed structural model, right for OCWFE.

The load corresponding to the double mouldboard $(4500 \mathrm{~N})$ is applied in the centre of its contact area with its support. The load corresponding to the blade $(2 \times 400 \mathrm{~N})$ is distributed in two equal components, on symmetrical areas in relation to the longitudinal axis of the structure, areas located on the connection support to the central resistance beam. The structure is meshed by probing, until the calculation program accepted the total meshing, fig. 2 .

The only important material constants in the linear-elastic calculation are: the modulus of longitudinal elasticity $\mathrm{E}=2.0 \cdot 10^{11} \mathrm{~Pa}$, the Poisson's ratio $v=0.29$. In addition, to estimate the safety factor of the structure, the yield stress with the value $351.571 \mathrm{MPa}$ (steel with AISI code 1020 from the material library of the Solid Works program, [16]) is retained.

\section{Results}

The important results retained from the elastic-linear static analysis of the OCWFE structural model, using the finite element method, are the fields of the relative displacement (deformation), the strain, and Cauchy stress. Based on these results, the first conclusions are drawn, which refer to the strength of the load-bearing structure in the work process and to the quality of the soil processing performed. For the two evaluations about the behaviour of the equipment in work, it is sufficient to consider in discussion only the equivalent stress field (Von Mises), fig. 4, and the resulting relative displacement field (deformation), fig. 3. The maximum value of the resulting relative displacement field is $4.58 \mathrm{~mm}$ (fig. 3), located on the model boundary at the end of the double mouldboard support. The maximum value of the equivalent stress is $186.642 \mathrm{MPa}$, located at the top of the double mouldboard support and at the connection points to the central tie rod of the tractor (fig. 4). The component with the highest intensity of the resulting relative displacement is the one along 
the Ox axis. The distribution of the values of this component on the border of the structural model is given in fig. 5. In fig. 6 is given the map of the distribution of the component values along the Oy axis (the vertical to the ground surface) of the relative displacement, on the border of the structural model of OCWFE.

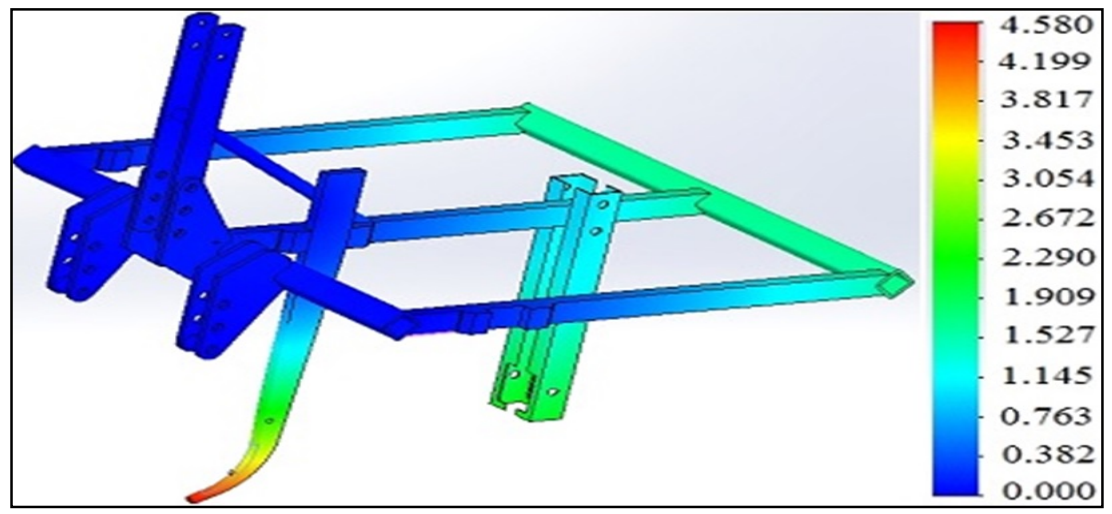

Fig. 3. Resultant displacement field on the model border, in $\mathrm{mm}$.

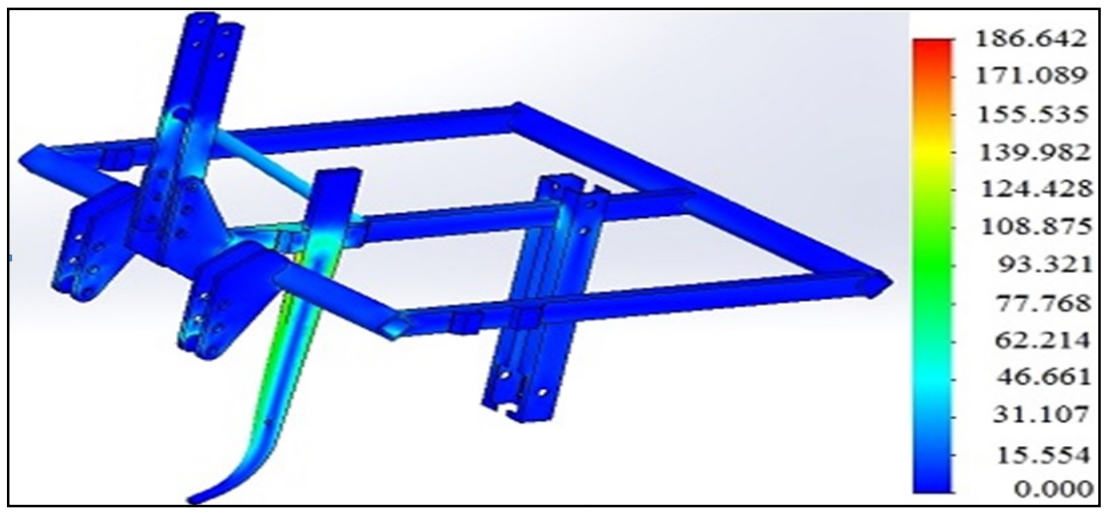

Fig. 4 Map of equivalent stress values on the model boundary, in MPa.

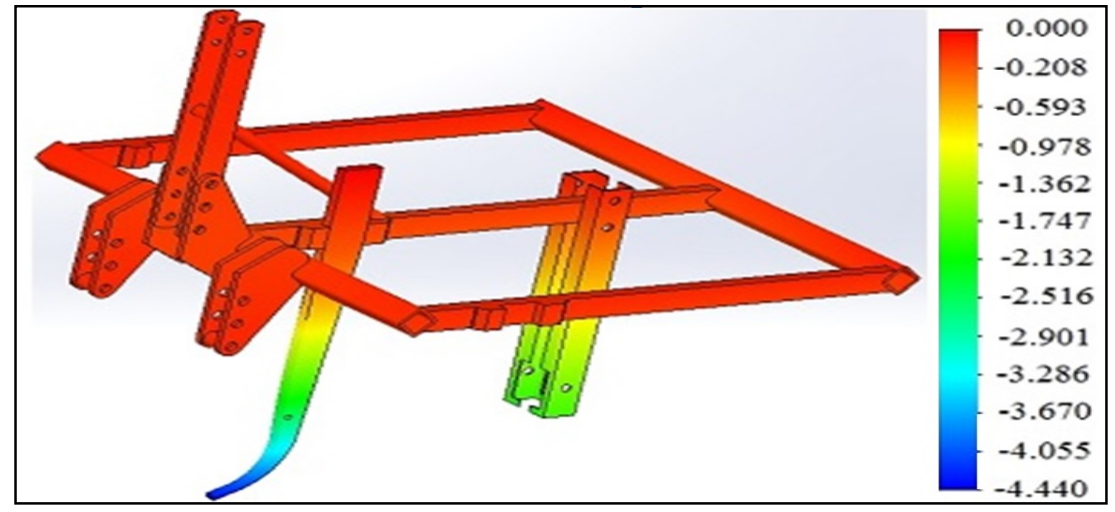

Fig. 5 Map of the distribution of the component values along the Ox axis of the relative displacement field, on the border of the structural model of OCWFE, in mm. 
Regarding the relative displacement of the structure along the $\mathrm{Oz}$ axis (transverse direction to the direction of movement in the horizontal plane) it varies, on the boundary of the structure, between -0.194 and $0.312 \mathrm{~mm}$. In general, this component is used to detect possible asymmetries in motion, phenomena that can give major effects in working process.

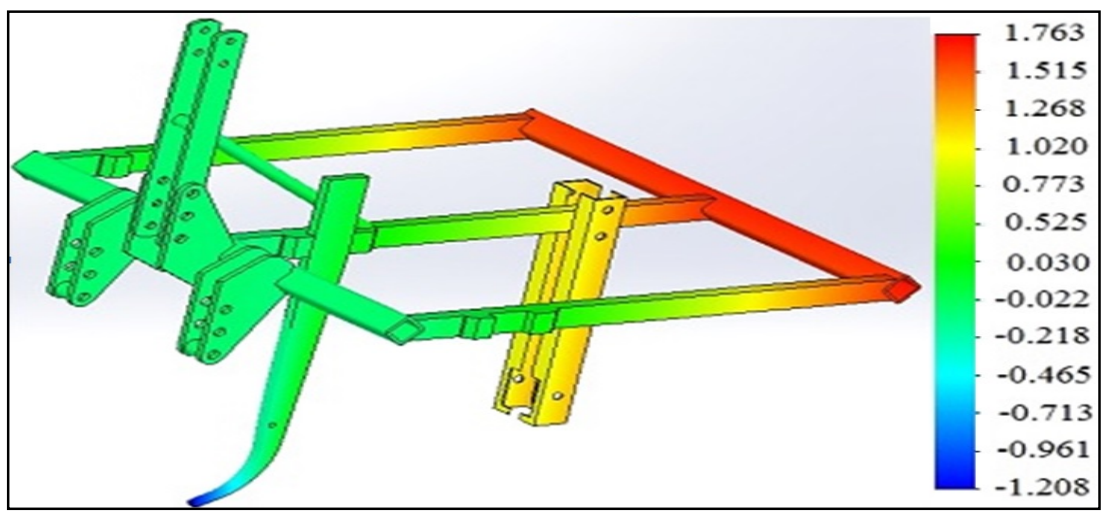

Fig. 6 Map of the distribution of the component values along the Oy axis of the relative displacement field, on the border of the structural model of OCWFE, in mm.

\section{Discussion}

The maximum value of the resulting relative displacement shows that the maximum deformation of the structure compared to the rest position is located at the base of the support of the double mouldboard that causes the same displacement of the double mouldboard, therefore, there is the possibility of a maximum vertical deviation of 2.29 $2.69 \%$ of the channel depth which must be produced by passing the machine (depth of 170 $200 \mathrm{~mm}$ ). The deviation is negligible considering that the soil can itself produce such deviations.

The maximum value of the stress registered in the upper area of the double mouldboard support is not dangerous, ensuring a safety factor with a minimum value of 1.88 , sufficient in relation to the standards for agricultural machines, [17]. In addition, the double mouldboard support has been simplified in the structural model used in this analysis, in reality being much more rigid. High values of equivalent tension in the tractor attachment area are negligible because the bearing is excessively rigid compared to reality (joints with large clearances).

In fig. 5 can be observed the distribution of the component values along the Ox axis of the relative displacement vector (deformation). This component has the dominant contribution to the resulting relative displacement. The analysis of the relative displacement on components shows that the absolute maximum value is concentrated on the $\mathrm{Ox}$ axis (direction of advance of the aggregate), in the opposite direction to the direction of advance (4.44 $\mathrm{mm}$, at the area where the double mouldboard is attached to its support). The component of the relative displacement on the Oy direction has the maximum value of $1.763 \mathrm{~mm}$, in the positive sense, i.e. the structure rises or tends to come out of the ground. This value is small than half the maximum of the resultant displacement value. Thus the error of achieving the working depth is much smaller than the one calculated above. In addition, the map of the distribution of the relative displacement on the border shows that the vertical lift is maximum at the rear of the load-bearing structure, and the minimum 
value (which is negative) is registered in the area where the double mouldboard is attached to its support. The negative sign of this component at the top of the double mouldboard support shows that the working body tends to enter deeper into the soil.

The values between which the transverse component varies with the direction of movement in the ground plane of the relative displacement (Oz axis), show that, although the structure is not symmetrical, the asymmetry in displacement is still negligible.

All the above considerations are valid in the hypothesis that the support of the structure (connection to the tractor) corresponds to reality. In reality, however, attaching the structure to the tractor is more complicated, including play joints, which makes it very difficult to model boundary conditions as a contact problem. For design needs, however, the information obtained in the case of rigid boundary conditions is sufficient.

The efficiency of a complex structural analysis for a load-bearing structure such as the strength frames of the agricultural machinery is still, a debatable problem, but it can be clarified then when there will be enough examples of analyzes at different levels of complexity for the same structure and the they results will be compared. Until then, there will be enough learned or brave people who will "shoot with the cannon at the sparrows". Generating 3D drawings to obtain the execution documentation is an operation that has transformed in these times, many engineers into simple designers. Many know how to generate complex curves and surfaces, which extruded give bodies with a very complex geometry. Then, such bodies are joined into assemblies by operations of translation and rotation in space. How many of these operators still know how to generate numerically, if not the curves and complex surfaces, at least the line, the circle, the spherical surface, the ellipsoid, etc. ? The black boxes, which are CAD programs, thus generate structural models that have small defects, called gaps or interferences, just as parts or subassemblies which are sets of disjoint points, or have non-empty intersections of non-zero 3D measurement. Such drawings or flat drawings, 2D or classic projections can be used successfully for the execution of physical models, because the human mind solves small errors such as gaps or interferences, obviously, when they are small enough and do not generate malfunctions. Solving such problems in execution practice is a matter of compromise between designer and executor, more difficult when the executor is a machine and needs the exact numerical model for an exact execution, with standardized tolerances.

The structural model prepared for the structural simulation must be carefully prepared so that the gaps and interferences are sufficiently reduced so that the calculation can tolerate them, possibly by introducing additional hypotheses. CAD-CAM models prepared by these 3D drawing programs (which generally have gaps and interference) have some errors generated by the set errors of the program when coupling different parts or assemblies, but at the same time they respect the tolerances of the standards, generating games without which the coupling of parts or assemblies becomes impossible. Structural calculation programs cannot tolerate large gaps and interferences. Small interferences are also difficult to tolerate and give rise to difficulties of mesh generation. However, small gaps are not only accidental but can often be necessary for installation. Even being small and regulatory from the point of view of execution, the existence of the necessary gaps requires, for numerical simulation, very large complications with contact problems. For this in the first stage of study, such gaps are tried to be tolerated by various procedures. However, these procedures, in general, do not correspond to reality. After eliminating gaps and interferences through various procedures (couplings, for example), the CAD-CAE model is obtained which will be subjected to structural analysis.

It is found that the analysis activity of a 3D structural model, meshed with solid elements, is long-lasting, expensive. It is not recommended to use such a method in the early stages of 
design, in which many solutions change (profiles, materials, shapes, variants). Changes in the structural geometry of these solutions will require redesign as well as all other operations described above. It is much more convenient to use, especially for load-bearing structures (resistance frames), 3D models, simple meshed with 1D finite elements, possibly mixed (hybrid). Such a model greatly reduces or even cancels the number of gaps and interferences. Complex 3D models are useful in the final design stage for determining stress concentrators, structure optimization or improvement activity based on information about the operation of the experimental model (elimination of intense vibrations, premature wear, etc.). In order for both types of models (meshed with 1D and 3D elements, respectively) to be fully accepted, in addition to experimental validation, a convergence study would also be needed, which is not simple, [18].

\section{Conclusions}

The results of the analysis show that the structural analysis of a resistance frame for agricultural machinery is useful primarily for checking the resistance, in the case of an experimentally determined work regime (demands, conditions on the border, etc.). This application is classic. The Cauchy tensor field is used and for global evaluation the equivalent stress or main stresses.

The 3D structural model allows repeated changes to the loading assumptions or boundary conditions, even the materials used. However, it is difficult to probe different solutions by changing the geometry. This operation requires the regeneration of the geometry and the resumption of the problem of eliminating gaps and interferences. In addition, a complete analysis would necessitate an operation that can usually be considered a luxury in solving the problem, namely the study of the convergence of the solution.

It is recommended that $3 \mathrm{D}$ structural models be used only in the final stage of calculation and simulation when there are no frequent changes in geometry or changes in the geometry of the loading and border conditions areas. Such models are mainly used to remedy the deficiencies noted in the experimental stage or in operation (as in the example presented in the article).

In order to optimize the structural analysis activity, it is recommended to seriously examine the efficiency of the structural analysis on complex models in approaching the problems of a structure from the category of those approached in this paper. There are a large number of simple structures for complex studies on 3D models are justified only at most for demonstration or learning purposes.

It must be taken into account that the CAD-CAE structures used in the structural analysis are through the hypotheses used, different from reality (couplings made through false hypotheses, the boundary conditions hypotheses and even the loading hypotheses). As a result, the validation of the structural models must be done experimentally, an activity in which it will be possible to motivate the differences between the theoretical and the experimental results.

\section{Acknowledgement}

This work was supported by a grant of the Romanian Research and Innovation Ministry (RRIM), through Programme 1 - Development of the national research-development system, subprogram 1.2 Institutional performance - Projects for financing excellence in RDI, contract no. 16PFE, and was done by "NUCLEU" Programme, developed with the support of the RRIM, project PN 19100102. 


\section{References}

1. A.W. Hendry, B.P. Sinha, S.R. Davies, Design of Masonry Structure, Taylor \& Francis, 7 (2004)

2. L.F.A. Bernardo (Editor), Architectural Structure, Applied Science, MDPI, (2020)

3. P. Cardei \& others, , Structural analysis and new materials focused on mechanics, mechatronics, maintenance and operation of technical equipment for agriculture and food industry, Terra Nova Publishing Iasi, (2012)

4. R. A. Tabile, E.P. Godoy, R.R.D. Pereira, G.T. Tangerino, A.J.V. Porto, R.Y. Inamasu, Design and development of the architecture of an agricultural mobile robot, Eng. Agric., 31 (1), 130-142, (2011)

5. J. Selech, D. Ulbrich, W. Kęska, Ż. Staszak, J. Marcinkiewicz, D. Romek, P. Rogoziński, Design of a cultivator mounted on a tractor with a power of up to $20 \mathrm{~kW}$, MATEC Web Conferences 254, 1-7, (2019)

6. R.Y. Garud, S.C. Tamboli, Structural Analysis of Automotive Chassis, Design Modificationnand Optimization, International Journal of Applied Engineerin Research, 13 (11), 9887-9892, (2018)

7. S.Șt. Biriș, E. Maican, V. Vladuț, S. Bungescu, Stress and strain distribution in the frame of agricultural cultivators using the finite element method, Proceedings of The 44 International Symposium on Agricultural Engineering "Actual Tasks on Agricultural Engineering" Opatija, 111-117, (2016)

8. N. Makange, R. Parmar, V. K. Tiwari, Stress Analysis on Tyne of Cultivator Using Finite Element Method, Trends in Biosciences 8(15), 3919-3923, (2019)

9. V. Vladut, E. Maican, L. Apostol, N. Ungureanu, I. Dumitru, R. Oprescu, Verification of Stress by FEM Analysis Mechanical Testing of Agricultural Mobile Aggregates Coupling Devices, INMATEH Agricultural Engineering, 54(1),39-46, (2018)

10. S. Șt. Biriș, Ungureanu N., Cujbescu D., Modelling of soil compaction under heavyduty tractors, INMATEH Agricultural Engineering, 57(1), 261-270, (2019)

11. G.A. Constantin, Gh. Voicu, B. Olac, F. Ilie, G. Paraschiv, V. Ştefan, G. Musuroi, Structural analysis with finite elements of a subsoiler working part, INMATEH Agricultural Engineering, 61(2), 61-26, (2020)

12. G. Ipate, G. A. Constantin, S. Șt. Biriş, Gh. Voicu, C. O. Rusănescu, V. Ștefan, Numerical 3D analysis a mini wind turbine with horizontal axis, for implementation in agricultural farms, INMATEH Agricultural Engineering, 61(3), 325-333, (2020)

13. V. Nițescu, P. Cardei, V. Muraru, I. Cojocaru, R. Sfîru, Modalităţi de dimensionare a cilindrului hidraulic pentru mecanismul de reversare al unui plug reversibil, folosind cinematica şi dinamica procesului de reversare, INMATEH Agricultural Engineering, 16(1), 163-168, (2006)

14. V. Muraru, N. Constantin, P. Cardei, R. Sfîru, Structural Analysis of MATINA soil working machine, INMATEH Agricultural Engineering, 31(2), 17-26, (2010)

15. M. Boryga, P. Kolodziej, Stress analysis of the sugar beet lifter with the finite element method (FEM), Agricultural Engineering, 23(3), 29-39,(2019)

16. Dassault Systemes, SolidWorks Help, https://help.solidworks.com/, (2021)

17. I. I. Ștefănescu, C. Spanu, Organe de mașini, vol. I, Editura Europlus, Galați, (2009)

18. P. Cardei, R. Sfîru, S. Muraru, V. Muraru, The convergence of structural models used in the geotechnical software, Proceedings of 17th International Multidisciplinary Scientific GeoConference SGEM, (2017) 
19. S.Şt. Biriş, V. Vlăduţ, N. Faur, A. Cernescu, O. Kabaş, M. Matache, I. Voicea, S. Bungescu, C. Popescu, FEM analysis / testing resistance of a tractor seat, Proceedings of the 43 International Symposium On Agricultural Engineering "Actual Tasks on Agricultural Engineering", Opatija, 189-200, (2015)

20. S.Şt. Biriş, N. Ungureanu, N.E. Gheorghiță, E. Maican, V. Vlăduț, Theoretical research on enhancing the performance of cultivators working bodies, Proceedings of the 45 International Symposium On Agricultural Engineering "Actual Tasks on Agricultural Engineering", Opatija, 121-130, (2017)

21. D. Cujbescu, S.Șt. Biriș, Gh. Voicu, M. Matache, G. Paraschiv, V.Vlăduţ, M. Bularda, N. Ungureanu, Determination of sowing precision in simulated laboratory conditions, INMATEH - Agricultural Engineering, 61(2), 209-216, (2020)

22. D. Cujbescu, N. Ungureanu, V. Vlăduţ, C. Persu, R. Oprescu, E. Gheorghiţă, Field testing of compaction characteristics for farm tractor universal 445, INMATEH Agricultural Engineering, 59(3), 245-252, (2019)

23. D.I. Vlăduţ, S. Biriş, V. Vlăduţ, D. Cujbescu, N. Ungureanu, I. Găgeanu, Verification of stress by FEM analysis / mechanical testing of agricultural mobile aggregates couplig device, INMATEH - Agricultural Engineering, 54(1), 37-462, (2018)

24. D.I. Vlăduţ, V. Vlăduţ, I. Grigore, S. Biriş, Experimental research on qualitative indices of work for equipment for seedbed preparation in conservative system, 16th International Scientific Conference "ENGINEERING FOR RURAL DEVELOPMENT", 1174-1179, Jelgava, Latvia, (2017)

25. V. Vlăduţ, V. Gângu, I. Pirnă, S. Băjenaru, S. Biriş, S. Bungescu, Complex tests of the resistance structures in simulated and accelerated regime on hydropulse installation, Proceedings of the 35 International Symposium On Agricultural Engineering "Actual Tasks on Agricultural Engineering", 393-404, Opatija - Croaţia, (2007)

26. V. Vlăduţ, Matache M., Faur N., Biriş S., Paraschiv G., Bungescu S., Traction bar testing of a $161 \mathrm{~kW}$ tractor in simulated and accelerated regime and its analysis by finite elements method for determining its rupture resistance, Proceedings of the 37 International Symposium On Agricultural Engineering "Actual Tasks on Agricultural Engineering", 77-84, Opatija - Croaţia, (2009)

27. V. Vlăduţ, S. Biriş, S. Bungescu, N. Faur, A. Cernescu, M. Matache, O. Kabaş, G. Paraschiv, At. Atanasov, Gh. Ivan, The verification of stress by MEF analysis/ mechanical testing of a traction bar, Proceedings of the 43 International Symposium On Agricultural Engineering "Actual Tasks on Agricultural Engineering", 141-152, Opatija - Croaţia, (2015)

28. V. Vlăduţ, E. Marin, I. Grigore, S.Șt. Biriş, N. Ungureanu, G. Gheorghe, M. Matache, C. Persu, I. Voicea, D. Cujbescu, S. Bungescu, I. Kiss, C. Vlad, Field and laboratory wear testing of integral seedbed implement's chisel tines point, Proceedings of the 45 International Symposium On Agricultural Engineering "Actual Tasks on Agricultural Engineering", 131-140, Opatija - Croaţia, (2017)

29. L. Vlăduţoiu, P. Cârdei, V. Vlăduţ, L. Fechete - Modern trends in designing and selecting the machine / equipment for soil deep tillage, 16th International Scientific Conference "ENGINEERING FOR RURAL DEVELOPMENT", 1415-1420, Jelgava, Latvia, (2017). 